\title{
REVIEW ARTICLE Microbiology and risk factors associated with war-related wound infections in the Middle East
}

\author{
Z. T. SAHLI ${ }^{1}$, A. R. BIZRI ${ }^{2 *}$ AND G. S. ABU-SITTAH ${ }^{3}$ \\ ${ }^{1}$ School of Medicine, American University of Beirut, Beirut, Lebanon \\ ${ }^{2}$ Division of Infectious Diseases, Department of Internal Medicine, American University of Beirut Medical \\ Centre, Beirut, Lebanon \\ ${ }^{3}$ Department of Surgery, Division of Plastic, Reconstructive and Aesthetic Surgery, American University of Beirut \\ Medical Centre Beirut, Lebanon
}

Received 7 January 2016; Final revision 15 February 2016; Accepted 15 February 2016; first published online 2 March 2016

\section{SUMMARY}

The Middle East region is plagued with repeated armed conflicts that affect both civilians and soldiers. Injuries sustained during war are common and frequently associated with multiple life-threatening complications. Wound infections are major consequences of these war injuries. The microbiology of war-related wound infections is variable with predominance of Gram-negative bacteria in later stages. The emergence of antimicrobial resistance among isolates affecting warrelated wound injuries is a serious problem with major regional and global implications. Factors responsible for the increase in multidrug-resistant pathogens include timing and type of surgical management, wide use of antimicrobial drugs, and the presence of metallic or organic fragments in the wound. Nosocomial transmission is the most important factor in the spread of multidrugresistant pathogens. Wound management of war-related injuries merits a multidisciplinary approach. This review aims to describe the microbiology of war-related wound infections and factors affecting their incidence from conflict areas in Iraq, Syria, Israel, and Lebanon.

Key words: Middle East, microbiology, multidrug resistance, wound.

\section{Introduction and Background}

The Middle East region is frequently associated with wars and military conflicts of which the Arab-Israeli wars and recent Arab uprisings are good examples [1]. There is a strong association between military conflicts and infectious diseases and historically classic 'war pestilence' such as plague, cholera, typhoid, typhus, dysentery, and smallpox are cited as being responsible for most of the deaths during wartime.

\footnotetext{
* Author for correspondence: A. R. Bizri, MD, American University of Beirut, P.O. Box 11-0236, Department of Internal Medicine, Division of Infectious Diseases, Riad El-Solh, Beirut 1107, 2020, Lebanon.

(Email: ab00@aub.edu.lb)
}

However, improvements in sanitation and public health infrastructure along with better practices relevant to troop deployment have led to a substantial decline in mortality associated with such infections [2]. The last century has also witnessed a significant drop in mortality resulting from infections caused by battle wounds [3]. Efforts to prevent or minimize morbidity and mortality resulting from combat-related injuries include better personal protective equipment, training of medical personnel to provide lifesaving procedures on the battleground, and setting medical care facilities with surgical capabilities close to point of injury. The ability to enhance survival rates in soldiers and civilians with war injuries has, nevertheless, resulted in an increase in the risk of wound infections 
in this group [4]. Experience gained during the Great War (World War I) helped in reducing the incidence and subsequent complications of battle wound infections. Taking patient mortality as a measure, aggressive surgical debridement, delayed primary closure, early surgical intervention, flaps, and external fixators, although on a limited scale, all contributed to better patient outcomes in World War II compared to World War I. The main lesson gained from World War II, where up to $86 \%$ of hospitalized patients experienced an infection, was the importance of nosocomial acquisition of bacteria thus emphasizing the importance of infection control and aseptic techniques $[4,5]$.

The microbial aetiology of combat-related injuries differs between various stages of management. Generally, bacterial transition occurs over time, from in the early stages an even balance of Gram-positive and Gram-negative flora, to the later predominance of antibiotic resistant Gram-negative species during treatment [6]. It is believed that antibiotics administered early at the time of injury exert a selection pressure leading to antimicrobial resistance [4]. The first large-scale utilization of antibiotics in battles was during D-Day in 1944 where penicillin was effectively used to protect injured soldiers from developing Clostridium infection and subsequent tetanus, but later in the Korean war, penicillin combined with streptomycin was the most widely used antibiotic regimen. Antibiotics were often administered prophylactically, but at a cost that only became apparent in retrospect, as resistant bacteria were increasingly reported from infected war wounds 3-5 days after injury. The significance of Pseudomonas aeruginosa and resistant Gram-negative and Gram- positive isolates was most obvious during the Vietnam war [7,8].

War injuries are not restricted to military personnel and since 1945, more than 100 million people, with 25 million deaths, have been recorded in military conflicts worldwide [9]. Characterizing and defining warzone injuries is a complicated process due to difficulty of access to those affected, limited healthcare personnel and facilities at site of injury, and the widespread use of antimicrobial drugs. Complete patient histories are also difficult to obtain in crisis settings, limiting the healthcare worker's ability to describe all prior interventions. Furthermore, injuries sustained during war are at high risk of infection due to environmental contamination [10].

The aim of this review is to describe the microbiology of war-related wound infections and factors affecting their incidence from conflict areas in Iraq, Syria, Israel, and Lebanon.

\section{Iraq}

Operation Iraqi Freedom/Operation Enduring Freedom resulted in a large number of injuries among both civilians and the military. The value of surveillance cultures was evaluated in a published report on 213 combat-related open Gustilo and Anderson type III diaphyseal tibia fractures among 192 US military personnel between March 2003 and September 2007 [11]. Surveillance cultures were positive in $64 \%$ of extremities and $93 \%$ of them grew Gram-negative isolates. By contrast, at 9 months following injury, 27\% developed a wound infection with mainly Gram-positive bacteria. In those with initial surveillance culture-positive wounds, $38.7 \%$ developed an infection compared to $11 \cdot 5 \%$ with negative surveillance culture wounds. Moreover, in subjects who subsequently developed a wound infection and had initial cultures taken, 26.2\% showed a match of at least one of the initial surveillance organisms. The contradiction between initial surveillance cultures and subsequent infected wound microbiology was attributed to the use of early antibiotic treatment, which suppressed the growth of susceptible flora and selected for more resistant organisms. The study concluded that patients culture positive on surveillance cultures were more likely to develop a wound infection and osteomyelitis. Even though positive surveillance cultures were not predictive of the infecting organism in subsequent infection, they were associated with development of wound infection, osteomyelitis, and ultimate need for amputation [11].

A smaller study of 49 US military casualties in Baghdad, Iraq during spring 2004, with acute open traumatic injuries that underwent aerobic culture of their wounds, found a bacterial contamination rate of $49 \%$ of cultures [12]. Gram-positive bacteria, mostly skincommensal flora, constituted $93 \%$ of positive cultures with only two isolates identified as methicillinresistant Staphylococcus aureus (MRSA) while Gramnegative bacteria were quite rare $(5 \%)$. These findings suggested that early wound bacteriology is composed predominantly of Gram-positive organisms of low virulence and pathogenicity, and that the use of broad-spectrum antibiotics against multidrug resistant (MDR) Gram-negative bacteria is unnecessary in early wound management [12].

MDR is defined as non-susceptibility to at least one agent in $\geqslant 3$ antimicrobial categories [13]. The role of 
MDR bacteria in causing wound infections and even bacteraemia was apparent in US military personnel in Iraq. Highly resistant pathogens mainly Acinetobacter baumannii-calcoaceticus complex (ABC), P. aeruginosa, extended spectrum $\beta$-lactamases (ESBLs) producing Klebsiella pneumoniae, Escherichia coli, and MRSA were frequently isolated from wound and bloodstream infections in American soldiers [14-17]. Data from combat support hospitals in Iraq during 2003 and 2004 revealed that coagulase-negative staphylococci accounted for $34 \%, S$. aureus for $26 \%$, and Streptococcus spp. for $11 \%$ of isolates. By contrast, cultures from the predominantly Iraqi population showed mainly $K$. pneumoniae (13\%), ABC (11\%), and P. aeruginosa $(10 \%)$ [18]. The total number of Gam-positive and Gram-negative isolates is not reported, but both showed resistance to a broad array of antibiotics [18]. In another study of US soldiers in Iraq and Afghanistan, the isolation of Candida spp. from penetrating wound injuries was associated with an increased risk of mortality [19]. However, a retrospective study of 48 British soldiers with an open fracture of the femur reported that four patients developed deep wound infections requiring surgical treatment and despite the low numbers of cases, the degree of bone loss rather than deep tissue infection was the factor most associated with outcome [20].

Little has been published about infections associated with war-related trauma in Iraqi soldiers and civilians. A study by the non-governmental organization Doctors Without Borders, found sepsis to be the most common cause of death in 1169 Iraqi patients admitted to a burns unit and $92 \%$ and $63 \%$ of Gram-positive and Gram-negative isolates, respectively, were classified as MDR [21]. The most common Gram-negative organisms were $P$. aeruginosa (34\%), K. pneumoniae (12\%), ABC (9\%), and Enterobacter cloacae (8\%), with S. aureus $(26 \%)$ and S. epidermidis $(11 \%)$ being the predominant Grampositive species [21].

\section{Syria}

The Syrian civil war, now in its fifth year, has resulted in $>200000$ deaths, 500000 wounded, and at least 9 million refugees [22, 23]. This war is an example of a military conflict that affects both civilians and soldiers and which has led to the destruction of the healthcare infrastructure in a limited-resources environment. A study by Doctors Without Borders of 61 Syrian orthopaedic patients with suspected infections found that
$74 \%$ had at least one positive wound culture, $13 \%$ of which were polymicrobial. Gram-negative organisms accounted for $56 \%$ of cultures with $P$. aeruginosa in $23 \%$, E. coli in $19 \%$, and ABC in $14 \%$; Gram-positive bacteria, including MRSA, represented $44 \%$ of isolates. Overall, $69 \%$ of patient harboured MDR organisms with MRSA representing $42 \%$ of staphylococcal isolates [10].

Since February 2013, the Syrian civil war has resulted in an influx of 1300 wounded, both fighters and civilians, into Israeli borders seeking medical treatment [24]. Among such patients, the incidence of MDR isolates ranged from $47 \%$ to $66 \%$, the most common being ESBL-producing and/or carbapenemresistant Enterobacteriaceae (CRE), MRSA and $\mathrm{ABC}$; two of the CRE isolates produced New Delhi metallo- $\beta$-lactamase $[25,26]$. Data for the first 100 patients from Syria admitted to the Ziv Medical Centre between February and October 2013 show that sepsis, due to delayed definitive wound care, was the main determinant of the clinical outcome. No correlation between time from injury to arrival to the trauma room and the incidence of septic complications was evident but an increased probability of sepsis was noted in wounds that had undergone primary closure to control haemorrhage and/or wrapped in soiled blankets before definitive care. For this reason, primary closure wounds warranted reopening, debridement, and vacuum-assisted closure systems [24].

Cited factors responsible for the increase in MDR organisms include delay in appropriate management, wide use of antimicrobial drugs without prescription in the community, and the presence of metallic or organic fragments in the wound $[10,27]$. It is recommended that in patients undergoing surgery such fragments must be removed or monitored for a long period of time [9]. However, several studies have shown that this does not apply for the central nervous system (CNS) injuries as no relationship was found between the presence of retained fragments and the development of either a seizure disorder or a CNS infection warranting the conclusion that it is unnecessary to re-operate for retained bone fragments, as they do not increase immediate or late complications [28-31]. The hospital setting is the major source of MDR organisms associated with blast injuries and nosocomial patient-patient transmission as well as faecal colonization with ESBL-producing Gram-negative bacteria often being responsible for acquisition of infection [25, 32]. Turton et al. showed the ABC strains responsible for wound infections in the United States 
and UK in American and British soldiers, respectively, who had shared exposure to various medical facilities, were genetically identical [33]. Nosocomial transmission has been reported to be a greater contributing factor to wound infection over environmental contamination at the time of injury [33-35].

This increase in MDR organisms has also translated to novel resistance at the molecular level. Carbapenem resistance in $66 \%$ of $\mathrm{ABC}$ isolates in Syria has been reported [36] and this was ascribed to the $b l a_{\mathrm{NDM}-1}$ gene in isolates from four Syrian patients, wounded in Syria, while being treated in Lebanon, which was the first time it was described in that country [37]. The $b l a_{\mathrm{NDM}-1}$ gene was first described in New Delhi in 2008 in Enterobacteriaceae [38] and differs from the most common acquired OXA-type resistance mechanism against carbapenemases [37, 39]. Data from Syrian hospitals on carbapenem resistance are lacking possibly due to the severe damage to healthcare infrastructure and the fact that Syrian doctors and health professionals are overwhelmed and understaffed dealing with the huge patient-care burden [40, 41].

\section{Israel}

Israel has witnessed numerous wars with bordering Arab countries. Medical military authorities during the Yom Kippur war recommended prophylactic penicillin administration to all wounded soldiers within $30-60 \mathrm{~min}$ after injury. In addition to penicillin prophylaxis, many hospitals added $1 \mathrm{~g} /$ day of streptomycin followed by oral 3-4 g/day of each of cloxacillin or ampicillin $[42,43]$. During that war, infection rates ranging from $4.9 \%$ to $58 \cdot 3 \%$ were reported with $P$. aeruginosa being the most common pathogen [4345], and this species was again the most prevalent in the ensuing 1982 war with Lebanon [46]. In both theatres the increased incidence of infection was associated with penetrating abdominal wounds involving the colon, extensive soft tissue loss, burns involving $>25 \%$ of the body surface, multiple operations, open drains inserted in the first operation, and wounds located below the diaphragm [42, 44, 46]. Infections due to penetrating abdominal wounds involving the colon can be due to heavy colonic bacterial flora mainly Bacteroides spp. and Enterobacteriaceae. For this reason, Simchen \& Sacks [44] recommended the prompt administration of clindamycin and gentamicin in combination for all abdominal injuries and treatment was continued for $48-72 \mathrm{~h}$ if colonic involvement was shown at laparotomy.
Despite its widespread use on the battlefield during the Yom Kippur war, the administration of prophylactic antibiotics did not have a significant impact in preventing wound infection [42]. Furthermore, this practice possibly contributed significantly to an increase in infections due to Gram-negative rods [47-51]. An increase in carbenicillin-resistant $P$. aeruginosa and gentamicin-resistant Klebsiella strains was noted in burn patients [45].

Candidaemia among immunocompetent patients following a bomb blast at an Israeli market place, which contained a significantly high concentration of airborne Candida organisms, was reported by Wolf et al. [52]. This infection was recorded in seven (30\%) of 21 patients between 4 and 16 days after the injury and Candida spp. was the most frequent cause of bloodstream infections, with inhalation injury appearing to be the best predictor of infection. Mortality in such patients was $43 \%$ and underlined the need to monitor patients for fungal infection where injuries were sustained in a similar setting and highlighted the wide range of organisms responsible for infected wounds through environmental exposure at the time of injury [52].

\section{Lebanon}

Lebanon has been plagued by wars and military conflicts since 1975 and the country has experienced, on several occasions, violent armed battles ranging from internal civil war to full-blown war with the Israeli Army. Over 40 years, the nature and intensity of military confrontations has varied, but the results remain the same - deaths and casualties among civilians and fighters [53]. Relatively few reports have been published describing battle injuries in Lebanon during the civil war (1975-1978) and the war with Israel (1982-2006) [29, 54-57]. In the civil war, a study of the management of 1021 Lebanese patients over a 10-year period (1975-1984) at a tertiary hospital reported an infection rate of $12 \%$ with $S$. aureus, $P$. aeruginosa, and $E$. coli being the most common organisms, respectively [55]. Another report from the same centre on the outcome of 1500 patients, described a $2 \cdot 1 \%$ incidence rate of sepsis as the second cause of death after haemorrhage $(3 \cdot 7 \%)[57]$.

In more recent times Lebanese hospitals have acted as referral centres for war casualties from Syria and Iraq as well as their own national soldiers and civilians. The variability in the source of injuries and 
the various approaches for early management at the point of injury adds further to the complexity of the treatment of such injuries [58] and risking the possibility of importation of MDR strains. In 2010 two NDM-1-producing $K$. pneumoniae imported from Iraq were detected in Lebanon [59] and between 2011 and 2013 a $60 \%$ prevalence rate of carbapenemresistant $\mathrm{ABC}$ was recorded in Tripoli, the largest Lebanese city bordering Syria [60], thus highlighting the need for effective measures to control the spread of such pathogens in the country.

Intracranial infections, including brain abscesses, following missile injuries to the brain were reported by the neurosurgery division at the American University of Beirut Medical Centre in patients treated between 1981 and 1988 [56]. More recently, the 2006 conflict with Israel, resulted in the release of more than four million sub-munitions over Lebanese soil including one million unexploded duds [61]. A study of 350 injured causalities by Fares et al. in 2013 revealed an infection rate overall of $19 \cdot 4 \%$ with bacterial infections accounting for $86.8 \%$ and fungi for the remainder. P. aeruginosa was the most common single isolate $(30 \cdot 5 \%)$ followed by $E$. coli [62]. This underlines the common finding that Gram-negative infections are generally more prevalent among war-related injuries compared to Gram-positive organisms and infected wounds are most often located below the diaphragm. Environmental contamination of penetrating pieces of clothes and metallic foreign objects increases the risk of streptococcal, staphylococcal and enterobacterial infections which are commonly found on skin or clothing covering the wound $[12,62,63]$.

\section{Treatment and prevention}

The use of prophylactic antibiotics for war-related trauma is controversial. Current guidelines of the Infectious Disease Society of America and the Surgical Infection Society for the prevention of infections associated with combat-related injuries strongly suggest that the use of broad-spectrum antibiotics at time of injury should be discouraged due to their potential to select resistant organisms. Furthermore, they do not support the use of aminoglycosides or fluoroquinolones for enhanced Gram-negative antimicrobial coverage as well as the administration of penicillin to prevent clostridial gangrene or streptococcal infection [64]. Velmahos et al. [65, 66] considered that in severe trauma patients the use of broad spectrum antibiotic coverage that includes MDR pathogens such as $\mathrm{ABC}$ is not needed at the time of injury, and administration of antibiotics for $>24 \mathrm{~h}$ does not offer additional protection against sepsis, organ failure, and death, but rather increases the probability of infection with MDR pathogens. However, the guidelines do advocate the administration of systemic antibiotics within $3 \mathrm{~h}$ post-injury to prevent infectious complications and sepsis. The choice of antibiotics depends on the location of the wound, with cefazolin preferred for extremity, central nervous system, and thorax wounds, and metronidazole for abdominal wounds; topical silver sulfadiazine and mafenide acetate are suggested for burn trauma [64].

$\mathrm{ABC}$ is a common pathogen in wound infections across the Middle Eastern region and the reported most active antimicrobial agents against these organisms are colistin, polymyxin $\mathrm{B}$, and minocycline [67-69]. Imipenem was originally recommended for prophylaxis against $\mathrm{ABC}$ organisms in war wounds but its empirical use is now discouraged, and should be reserved for management of a proven or suspected $A B C$ infection [70]. Injuries sustained in certain environmental settings may predispose to fungal colonization thus warranting antifungal prophylaxis with fluconazole [52, 62].

Wound debridement and delayed primary closure including the removal of possible foreign debris, first introduced in World War II [71], have been shown to significantly decrease the incidence of infection on admission $[42,72]$. Primary wound closure after debridement creates tension at the wound edges, which consequently compromises blood supply, increases the risk of infection and wound dehiscence [58]. Early drainage of haemothoraces, avoidance of thoracotomy as primary treatment, and the separate treatment of abdominal and thoracic injuries have also contributed to lower infection rates in patients with chest injuries [43, 73]. In countries such as Syria, where bacterial resistance is likely as a result of wide over-the-counter use of antibiotics [26, 74], hospitals in bordering countries receiving casualties are taking extra measures to ensure appropriate infection control practices including routine microbiological screening on admission, the use of a specific trauma room for immediate resuscitation, and the introduction of isolation bays on the wards [24].

A system for the treatment and prevention of war trauma-related wounds has been an evolving discipline since World War I. Currently, the gold standard approach used by the US military consists of four levels of care divided according to proximity to the 
Table 1. Summary of published reports describing the microbiology of war wound infections in Iraq, Syria, Israel, and Lebanon

\begin{tabular}{|c|c|c|c|c|c|c|}
\hline Military/civilian & Study sample & Site & Infection rate & Outcome & $\begin{array}{l}\text { Most common } \\
\text { organism }\end{array}$ & Study \\
\hline \multicolumn{7}{|l|}{ Iraq } \\
\hline British military & 48 & Open femur fractures & $8 \cdot 33 \%$ & $4 \%$ underwent amputation & S. aureus & {$[20]$} \\
\hline US military & 300 & $\begin{array}{l}\text { Lower extremity } \\
\text { amputations }\end{array}$ & $27 \%$ & $53 \%$ underwent reoperation & n.s. & [72] \\
\hline British military & 182 & Chest & $10 \cdot 44 \%$ & $4 \cdot 9 \%$ overall mortality & n.s. & [73] \\
\hline US military & 192 & $\begin{array}{l}\text { Diaphyseal tibia } \\
\text { fractures }\end{array}$ & $27 \%$ & $22 \%$ underwent amputation & $\begin{array}{l}\text { ABC (surveillance) } \\
\text { S. aureus (infected) }\end{array}$ & {$[11]$} \\
\hline US military & 16742 & Variable & $5 \cdot 5 \%$ & $0 \cdot 6 \%$ overall mortality & Gram negatives & {$[6]$} \\
\hline Civilian & 137 & Chronic osteomyelitis & $78 \%$ & n.s. & S. aureus & {$[32]$} \\
\hline Military and civilian & 211 & Variable & $26 \cdot 5 \%$ & $3.57 \%$ mortality among infected & $\mathrm{ABC}$ & {$[17]$} \\
\hline US military & 49 & Variable & $49 \%$ & n.s. & $\begin{array}{l}\text { Coagulase-negative } \\
\text { staphylococci }\end{array}$ & [12] \\
\hline \multicolumn{7}{|l|}{ Syria } \\
\hline Civilian & 100 & Variable & $12 \%$ & $2 \%$ overall mortality & n.s. & {$[24]$} \\
\hline Military and civilian & 66 & Cranial trauma & $10 \cdot 6 \%$ & $4 \cdot 5 \%$ overall mortality & n.s. & {$[31]$} \\
\hline Military and civilian & 345 & Variable & $18 \%$ & n.s. & P. aeruginosa & {$[10]$} \\
\hline Military and civilian & 186 & Cranial trauma & $6 \cdot 45 \%$ & $31 \cdot 7 \%$ overall mortality & n.s. & [9] \\
\hline \multicolumn{7}{|l|}{ Israel } \\
\hline Civilian & 21 & Variable & $30 \%$ with Candida & $43 \%$ mortality with candidaemia & Candida & {$[52]$} \\
\hline Military & $\begin{array}{l}\text { Group 1982: } 184 \\
\text { Group 1973: } 130\end{array}$ & Extremities & $\begin{array}{l}\text { Group 1982: } 30 \cdot 5 \% \\
\text { Group 1973: } 31 \cdot 5 \%\end{array}$ & n.s. & P. aeruginosa & {$[46]$} \\
\hline Military and civilian & 41 & Burns & $58 \cdot 53 \%$ & $14 \cdot 61 \%$ overall mortality & P. aeruginosa & {$[45]$} \\
\hline Military & 420 & Variable & $22 \%$ & $\begin{array}{l}1.90 \% \text { overall mortality } 1 \cdot 20 \% \\
\text { mortality from infection }\end{array}$ & $P$. aeruginosa & {$[44]$} \\
\hline Military and civilian & 142 & Chest trauma & $4 \cdot 9 \%$ & $7 \cdot 75 \%$ overall mortality & n.s. & {$[43]$} \\
\hline Military & 624 & Variable & $12 \cdot 5 \%$ & 6 cases of bacterial sepsis & P. aeruginosa & [42] \\
\hline \multicolumn{7}{|l|}{ Lebanon } \\
\hline Military and civilian & 350 & $\begin{array}{l}\text { Total body cluster } \\
\text { munitions }\end{array}$ & $19 \cdot 4 \%$ & $0.85 \%$ bacteremia & P. aeruginosa & {$[62]$} \\
\hline Military and civilian & 272 & Cranial trauma & $11 \cdot 39 \%$ & n.s. & n.s. & [29] \\
\hline Military and civilian & 1021 & $\begin{array}{l}\text { Head and neck } \\
\text { injuries }\end{array}$ & $12 \%$ & n.s. & S. aureus & {$[55]$} \\
\hline
\end{tabular}

ABC, Acinetobacter baumannii complex; n.s., not stated. 
battlefield and type of management. The first level consists of initial care in the battlefield and includes stabilizing fractures, bandaging wounds with sterile dressings, and administration of single dose antimicrobials if evacuation is delayed. Level-2 care takes place in a field hospital and consists of tetanus vaccinations and immunoglobulin administration, wound irrigation with saline to remove gross environmental contamination, and topical antimicrobials for burns. Combat support hospitals provide level-3 treatment with inpatient care, intensive care units, and operating rooms; this also includes surgical wound management with external fixation of open fractures, in addition to treatment provided at level 2. Finally, level-4 treatment is provided by regional hospitals or hospital ships, located outside the battlefield area, and covers general and specialized inpatient medical and surgical care [64]. Despite the success of this system in reducing morbidity and mortality, its implementation requires large amounts of financial and logistical resources, which are beyond the capability of most national armies. Wars in the Middle East including the US-led 'War on Terror' increasingly involve smaller nation armies and paramilitary groups that do not have such healthcare systems in place and as a consequence, civilian medical centres and hospitals in countries such as Iraq, Lebanon, and Syria bear the major burden of these conflicts.

\section{Conclusion}

The near complete destruction of healthcare-related infrastructure and hospitals in conflict areas, mainly Syria, has obliged injured individuals to seek treatment elsewhere primarily in neighbouring countries. The porous borders between countries in the region and the flight of refugees to adjacent areas have resulted in further draining of the limited public health resources available. In the absence of well-equipped military hospitals, civilian medical centres are bearing the major responsibility of handling those patients.

Table 1 summarizes published reports of conflict wound infections in civilians and military personnel according to country of study and describes the study sample size, wound infection rate, study outcome, and most common organism grown on culture. Study outcomes varied between rate of amputation, mortality, sepsis, bacteraemia, and re-operation. Infection rates range from $4.9 \%$ to $78 \%$ with $P$. aeruginosa, $\mathrm{ABC}$, and $S$. aureus among the most common organisms reported causing wound infection.
The free movement of injured fighters and civilians has facilitated the transmission of MDR pathogens. The term 'Iraqibacter' used by the Americans to describe the emerging $A B C$ problem following the Iraq war can be applied to many settings including Lebanon, Jordan, and Israel so much so that Iraqi patients are screened for a wide range of MDR pathogens before being released from isolation following admission to Lebanese hospitals. Since these organisms in war-related wounds are on the increase, it is important to disseminate and implement infection control practices to prevent their further emergence and transmission as nosocomial transmission is the most important factor determining the extent of spread in hospitals. Other contributing factors include the environment of injury, site of injury, and initial choice of antibiotics.

The effective management of war-related injuries requires a multidisciplinary approach where surgeons from various disciplines as well as other infectious diseases specialist medical and nursing personnel are involved. Despite the vast discrepancy in available resources, regional health authorities could learn from the American military experience where initial management at the site of injury and rapid transport to the closest available medical facility has been shown to positively affect patient outcome. Unwarranted surgical interventions such as early closure and the overuse of broad-spectrum antibiotics will have a negative impact on the incidence and microbiology of wound infection and the patient's morbid complications.

Despite numerous wars and conflicts in the Middle East, there are few large-scale microbiological studies of conflict-related trauma and appropriate clinical management from the region. As the violence continues, with no sign of abating, more studies with larger sample sizes are needed to build adequate regional and local expertise leading to formation of appropriate guidelines for the region.

\section{Declaration of Interest}

None.

\section{References}

1. Fawcett L. International Relations of the Middle East 3rd edn. Oxford, United Kingdom: Oxford University Press, 2013: pp. 424. 
2. Murray CK, et al. An approach to prevention of infectious diseases during military deployments. Clinical Infectious Diseases 2007; 44: 424-430.

3. Smallman-Raynor MR, Cliff AD. Impact of infectious diseases on war. Infectious Disease Clinics of North America 2004; 18: 341-368.

4. Murray CK. Infectious disease complications of combat-related injuries. Critical Care Medicine 2008; 36: S358-S364.

5. Pruitt Jr. BA. Combat casualty care and surgical progress. Annals of Surgery 2006; 243: 715-729.

6. Murray CK, et al. Infections complicating the care of combat casualties during operations Iraqi Freedom and Enduring Freedom. Journal of Trauma 2011; 71 (Suppl. 1): S62-73.

7. Manring M, et al. Treatment of war wounds: a historical review. Clinical Orthopaedics and Related Research 2009; 467: 2168-2191.

8. Kovaric J, et al. Bacterial flora of one hundred and twelve combat wounds. Military Medicine 1968; 133: 622-624.

9. Aras M, et al. Being a neighbor to Syria: A retrospective analysis of patients brought to our clinic for cranial gunshot wounds in the Syrian civil war. Clinical Neurology and Neurosurgery 2014; 125: 222-228.

10. Teicher CL, et al. Antimicrobial drug-resistant bacteria isolated from Syrian war-injured patients, August 2011March 2013. Emerging Infectious Diseases 2014; 20: 1949-1951.

11. Burns TC, et al. Microbiology and injury characteristics in severe open tibia fractures from combat. Journal of Trauma and Acute Care Surgery 2012; 72: 1062-1067.

12. Murray CK, et al. Bacteriology of war wounds at the time of injury. Military Medicine 2006; 171: 826-829.

13. Magiorakos AP, et al. Multidrug-resistant, extensively drug-resistant and pandrug-resistant bacteria: an international expert proposal for interim standard definitions for acquired resistance. Clinical Microbiology and Infection 2012; 18: 268-281.

14. Calhoun JH, Murray CK, Manring MM. Multidrugresistant organisms in military wounds from Iraq and Afghanistan. Clinical and Orthopedic Related Research 2008; 466: 1356-1362.

15. Bennett JE, Dolin R, Blaser MJ. Mandell, Douglas, and Bennett's Principles and Practice of Infectious Diseases: Elsevier Health Sciences, 2014, pp. 3905-3910.

16. Davis KA MK,McAllister CK, Gray PJ. Acinetobacter baumannii infections among patients at military medical facilities treating injured U.S. service members, 20022004. Morbidity and Mortality Weekly Rreport 2004; 53: 1063-1066.

17. Petersen K, et al. Trauma-related infections in battlefield casualties from Iraq. Annals of Surgery 2007; 245: 803-811.

18. Yun HC, et al. Bacteria recovered from patients admitted to a deployed US military hospital in Baghdad, Iraq. Military Medicine 2006; 171: 821-825.

19. Blyth DM, et al. Resistance patterns and clinical significance of Candida colonization and infection in combatrelated injured patients from Iraq and Afghanistan.
Open Forum Infectious Diseases 1(3). doi:10.1093/ofid/ ofu109.

20. Bennett $\mathbf{P}$, et al. The management and outcome of open fractures of the femur sustained on the battlefield over a ten-year period. Bone \& Joint Journal 2015; 97: 842846.

21. Ronat J-B, et al. Highly drug-resistant pathogens implicated in burn-associated bacteremia in an Iraqi Burn Care Unit. PLoS ONE 2014; 9: e101017.

22. Migration Policy Center. Syrian Refugees: A snapshot of the crisis in the Middle East and Europe, 2014 (http://syr ianrefugees.eu/?page_id=10). Accessed 15 February 2016.

23. Guha-Sapir D, et al. Civilian deaths from weapons used in the Syrian conflict. British Medical Journal 2015; 351.

24. Biswas S, et al. Analysis of the first 100 patients from the Syrian civil war treated in an Israeli District Hospital. Annals of Surgery 2016; 263: 205-209.

25. Peretz A, et al. Disengagement does not apply to bacteria: a high carriage rate of antibiotic-resistant pathogens among Syrian civilians treated in Israeli hospitals. Clinical Infectious Diseases 2014; 59: 753-754.

26. Al-Assil B, Mahfoud M, Hamzeh AR. Resistance trends and risk factors of extended spectrum $\beta$-lactamases in Escherichia coli infections in Aleppo, Syria. American Journal of Infection Control 2013; 41: 597-600.

27. Al-Faham Z, Habboub G, Takriti F. The sale of antibiotics without prescription in pharmacies in Damascus, Syria. Journal of Infection in Developing Countries 2011; 5: 396-399.

28. Carey ME. The treatment of wartime brain wounds: traditional versus minimal debridement. Surgical Neurology 2003; 60: 112-119.

29. Nohra G, et al. Infections after missile head injury. Experience during the Lebanese civilian war. Neuro-Chirurgie 2002; 48: 339-344.

30. Brandvold B, et al. Penetrating craniocerebral injuries in the Israeli involvement in the Lebanese conflict, 19821985: analysis of a less aggressive surgical approach. Journal of Neurosurgery 1990; 72: 15-21.

31. Barhoum M, et al. Syria civil war: Outcomes of humanitarian neurosurgical care provided to Syrian wounded refugees in Israel. Brain Injury 2015; 29: 1370-1375.

32. Murphy RA, et al. Multidrug-resistant chronic osteomyelitis complicating war injury in Iraqi civilians. Journal of Trauma and Acute Care Surgery 2011; 71: 252-254.

33. Turton JF, et al. Comparison of Acinetobacter baumannii isolates from the United Kingdom and the United States that were associated with repatriated casualties of the Iraq conflict. Journal of Clinical Microbiology 2006; 44: 2630-2634.

34. Kader AA, Kumar A, Kamath KA. Fecal carriage of extended-spectrum $\beta$-lactamase-producing Escherichia coli and Klebsiella pneumoniae in patients and asymptomatic healthy individuals. Infection Control 2007; 28: 1114-1116.

35. Vento TJ, et al. Multidrug-resistant gram-negative bacteria colonization of healthy US military personnel in the US and Afghanistan. BioMed Central Infectious Diseases 2013; 13: 68-79. 
36. Hamzeh AR, Al Najjar M, Mahfoud M. Prevalence of antibiotic resistance among Acinetobacter baumannii isolates from Aleppo, Syria. American Journal of Infection Control 2012; 40: 776-777.

37. Rafei R, et al. First report of bla NDM-1-producing Acinetobacter baumannii isolated in Lebanon from civilians wounded during the Syrian war. International Journal of Infectious Diseases 2014; 21: 21-23.

38. Yong D, et al. Characterization of a new metallo$\beta$-lactamase gene, blaNDM-1, and a novel erythromycin esterase gene carried on a unique genetic structure in Klebsiella pneumoniae sequence type 14 from India. Antimicrobial Agents and Chemotherapy 2009; 53: 5046-5054.

39. Baroud M, et al. Underlying mechanisms of carbapenem resistance in extended-spectrum $\beta$-lactamaseproducing Klebsiella pneumoniae and Escherichia coli isolates at a tertiary care centre in Lebanon: role of OXA-48 and NDM-1 carbapenemases. International Journal of Antimicrobial Agents 2013; 41: 75-79.

40. Stone-Brown K. Syria: a healthcare system on the brink of collapse. British Medical Journal 2013; 347.

41. Dewachi O, et al. Changing therapeutic geographies of the Iraqi and Syrian wars. Lancet 2014; 383: 449-457.

42. Klein RS, Berger SA, Yekutiel P. Wound infection during the Yom Kippur war: observations concerning antibiotic prophylaxis and therapy. Annals of Surgery 1975; 182: $15-21$.

43. Romanoff H. Prevention of infection in war chest injuries. Annals of Surgery 1975; 182: 144-149.

44. Simchen E, Sacks T. Infection in war wounds: experience during the 1973 October War in Israel. Annals of Surgery 1975; 182: 754-761.

45. Sidi Y, et al. Infectious complications of burns casualties during the Yom-Kippur war. Infection 1977; 5: 214-218.

46. Simchen E, et al. Risk factors for infection in fracture war wounds (1973 and 1982 wars, Israel). Military Medicine 1991; 156: 520-527.

47. Finland M. Changing ecology of bacterial infections as related to antibacterial therapy. Journal of Infectious Diseases 1970; 122: 419-431.

48. Louria DB, Brayton RG. The efficacy of penicillin regimens: With observations on the frequency of superinfection. Journal of the American Medical Association 1963; 186: 987-990.

49. McCabe WR, Jackson GG. Gram-negative bacteremia: I. Etiology and ecology. Archives of Internal Medicine 1962; 110: 847-855.

50. Weinstein L, Musher DM. Antibiotic-induced suprainfection. Journal of Infectious Diseases 1969; 119: 662-665.

51. Tillotson JR, Finland M. Bacterial colonization and clinical superinfection of the respiratory tract complicating antibiotic treatment of pneumonia. Journal of infectious diseases 1969; 119: 597-624.

52. Wolf DG, et al. High rate of candidemia in patients sustaining injuries in a bomb blast at a marketplace: a possible environmental source. Clinical Infectious Diseases 2000; 31: 712-716.
53. Winslow C. Lebanon: War and Politics in a Fragmented Society. New York: Routledge, 1996, pp. 360.

54. Sfeir RE, et al. Injury to the popliteal vessels: The Lebanese war experience. World Journal of Surgery 1992; 16: 1156-1159.

55. Zaytoun G, Shikhani A, Salman S. Head and neck war injuries: 10-year experience at the American University of Beirut Medical Center. Laryngoscope 1986; 96: 899-903.

56. Taha JM, Haddad FS, Brown JA. Intracranial infection after missile injuries to the brain: report of 30 cases from the Lebanese conflict. Neurosurgery 1991; 29: 864-868.

57. Nassoura $\mathbf{Z}$, et al. Trauma management in a war zone: the Lebanese war experience. Journal of Trauma and Acute Care Surgery 1991; 31: 1596-1599.

58. Bakhach J, Abu-Sitta G, Dibo S. Reconstruction of blast injuries of the hand and upper limb. Injury 2013; 44: $305-312$.

59. El-Herte RI, et al. Detection of carbapenem-resistant Escherichia coli and Klebsiella pneumoniae producing NDM-1 in Lebanon. Journal of Infection in Developing Countries 2012; 6: 457-461.

60. Rafei R, et al. Molecular epidemiology of Acinetobacter baumannii in different hospitals in Tripoli, Lebanon using bla OXA-51-like sequence based typing. $B M C$ Microbiology 2015; 15: 103-110.

61. Beehner L. The campaign to ban cluster bombs. In: Backgrounder. Council on Foreign Relations, 2012 (http://www.cfr.org/weapons-of-mass-destruction/cam paign-ban-cluster-bombs/p12060). Accessed 15 February 2016.

62. Fares Y, et al. Trauma-related infections due to cluster munitions. Journal of Infection and Public Health 2013; 6: 482-486.

63. Korzeniewski K. Health hazards in areas of military operations conducted in different climatic and sanitary conditions. International Maritime Health 2011; 63: 41-62.

64. Hospenthal DR, et al. Guidelines for the prevention of infections associated with combat-related injuries: 2011 update: endorsed by the Infectious Diseases Society of America and the Surgical Infection Society. Journal of Trauma and Acute Care Surgery 2011; 71: S210-S234.

65. Velmahos GC, et al. Prophylactic antibiotics after severe trauma: more is not better. International Surgery 2000; 86: $176-183$.

66. Velmahos GC, et al. Severe trauma is not an excuse for prolonged antibiotic prophylaxis. Archives of Surgery 2002; 137: 537-542.

67. Griffith ME, et al. Acinetobacter skin colonization of US Army soldiers. Infection Control 2006; 27: 659-661.

68. Griffith ME, et al. Acinetobacter skin carriage among US army soldiers deployed in Iraq. Infection Control 2007; 28: 720-722.

69. Scott P, et al. An outbreak of multidrug-resistant Acinetobacter baumannii-calcoaceticus complex infection in the US military health care system associated with military operations in Iraq. Clinical Infectious Diseases 2007; 44: 1577-1584.

70. Hawley JS, et al. Susceptibility of Acinetobacter strains isolated from deployed US military personnel. 
Antimicrobial Agents and Chemotherapy 2007; 51: 376378.

71. Churchill ED. Management of Wounds (Initial and Reparative Surgery). Symposium on Treatment of Trauma in the Armed Forces. Washington, Army Medical Service Graduate School WRAMC, 1952.

72. Tintle SM, et al. Reoperation after combat-related major lower extremity amputations. Journal of Orthopaedic Trauma 2014; 28: 232-237.
73. Senanayake EL, et al. UK specialist cardiothoracic management of thoracic injuries in military casualties sustained in the wars in Iraq and Afghanistan. European Journal of Cardio-Thoracic Surgery 2014; 45: 3202-3207.

74. Otoom S, Sequeira R. Health care providers' perceptions of the problems and causes of irrational use of drugs in two Middle East countries. International Journal of Clinical Practice 2006; 60: 565-570. 